\title{
Infrastructure risk-oriented advantages of low-power nuclear power plants
}

\author{
Udyanskiy Yu. N., Shchepetina T. D. \\ NRC “Kurchatov Institut”, Moscow, Russia
}

\begin{abstract}
Variants of classification of risks of NPP design over the entire life cycle are proposed. The concept of integral risk is introduced and, on its basis, approaches to the creation of a low-risk nuclear power system based on small and medium power units are formulated. The key role of the human factor in the formation of risks is reflected. Comparison of the risks of NPPs of large and small capacity is carried out. .
\end{abstract}

\section{Introduction}

Absolute safety cannot exist in principle. There is always some level of danger. The measure of the hazard level is the risk. There are many ways to assess it in various areas of human activity. Based on the many publications in the media, it can be concluded that, no matter how accurate the risk assessments are, they are not very convincing to the population.

If we begin to analyze the origin of the "risk" and then the reaction to its prevention, then involuntarily we are faced with a key point: "Human factor". It is believed that all adverse events are of an uncertain, random nature. From the point of view of the laws of nature, one cannot but agree with this. But where there is a person with his own free will in decision-making, there is soil for the "human factor" (HF) - and there will always be risk. And usually people look for ways to minimize it in one way or another. The research question, which the authors put before themselves, is the opposite: is it possible to find ways or methods of nuclear energy development, in which the HF, even being maximally "negatively implemented", will lead to the least adverse consequences.

Anthropogenic risk - the human factor - is not specific to the nuclear industry, but due to the possibility of a multiplying effect and the special danger of the industry as a whole, it deserves to pay attention to it and try to find any radical ways to neutralize it.

Man (personality), nature (environment), state (social society) are interconnected parts, subsystems of a single system, which are in synergistic interaction. The safety of any of these subsystems cannot be considered in isolation from the safety of other parts and outside the system as a whole, without taking into account such properties as the synergistic sum of the system. Sources of risks (hazards) are unevenly located in space and time and can synergistically interact with each other (domino effect).

To limit the danger and ensure the safety of project execution in the energy sector, all types of threats and risks in the preparation and implementation of projects should be taken into account and, if possible, minimized. At present, it is considered a generally accepted conclusion about the leading role of the human factor in ensuring the reliability of NPP operation. On this issue, scientists were divided into two categories: those who believe that all accidents, disasters, adverse events, etc. are of a random, stochastic nature, and those who see anthropogenic influence and the human factor to blame for all events.

\section{Approach to nuclear power plant risk classification}

There are many ways to classify risks and their sources (including in nuclear power). In this work, as a base, the analysis of risks by the stages of the NPP project life cycle is taken: strategic concept, research and development, development, design, construction, operation, decommissioning [1, 2].

Figures 1-5 shows one of the many possible ways of general classification of risks. It can be seen that there are groups of risks of a limited sphere of influence, there are "multi-group" (corruption, reputational) risks, but the "human factor" can become a source of trouble in all areas of the life cycle (LC) of the project.

If we accept the "human factor" as characterizing the quality of decision-making and execution, then although this phenomenon deserves a separate and comprehensive study, in this context it can be "rounded up" to a role in risk management in terms of the adequacy of competencies (experience and qualifications) at all stages of the life cycle of the project.

The following are approximate "risk maps" for all stages of the NPP project life cycle.

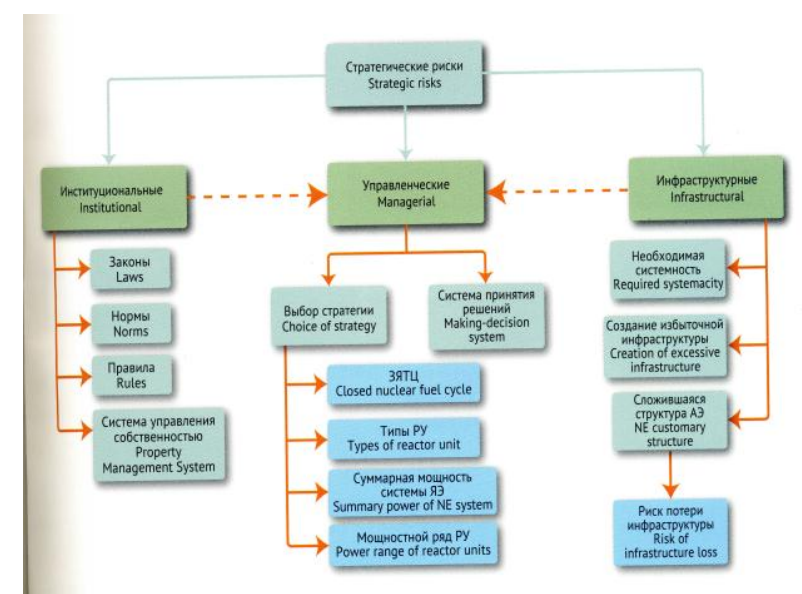

Fig. 1. Risks and their sources at the stage of strategic design

\footnotetext{
* Corresponding author: Schepetina TD@nrcki.ru
} 


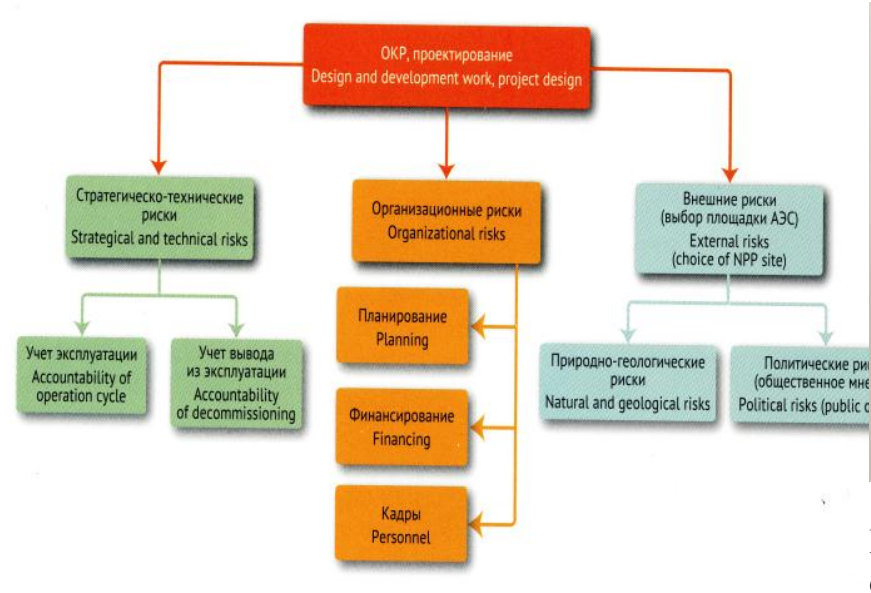

Fig. 2. Risks and their sources at the stages of research, development and design

The presented options for the classification of risks are far from being complete and final, since, in fact, risks can be both simple and combining multidirectional effects. Simple risks are determined by a complete list of non-overlapping events, i.e. each of them is viewed as independent of the others. Complex risks, as a rule, have intergroup links according to sources of occurrence and consequences.

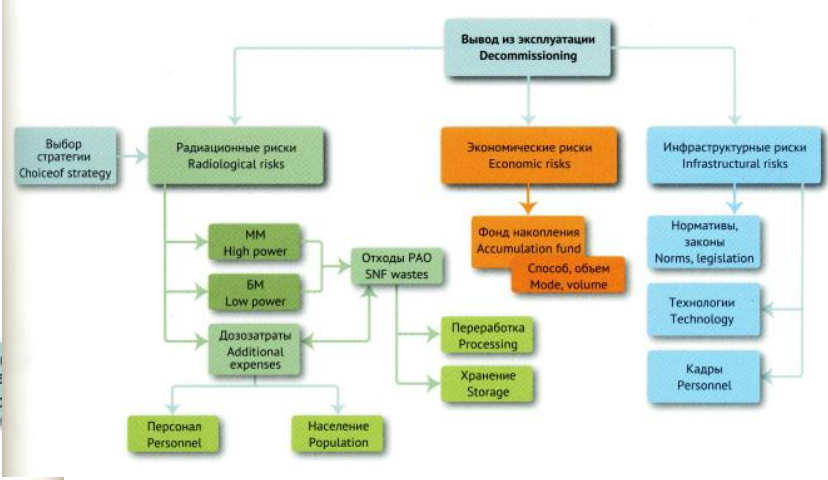

Fig. 4. Risks and their sources at the stage of decommissioning a power unit

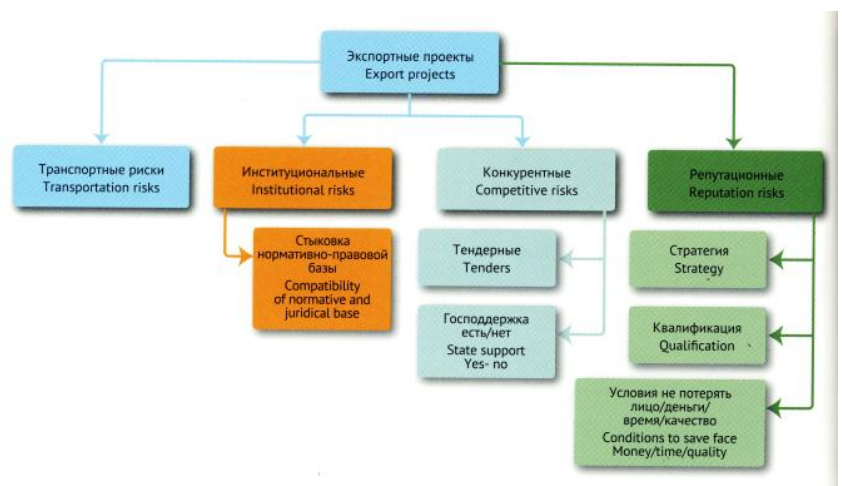

Fig. 5. Risks and their sources at the export

As a result, it is possible to introduce the concept of integral risk of a nuclear power plant project, as the sum of the "spatial and temporal components" of risks accompanying the project from conception to liquidation

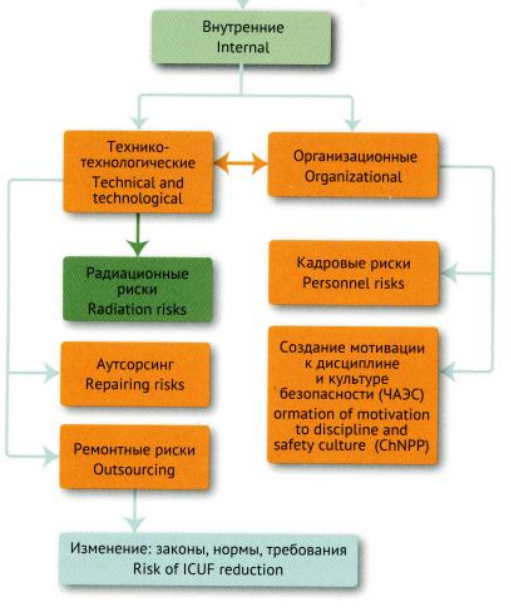

Fig. 3. Risks and their sources at the stage of power unit operation

Only a small fraction of the risks discussed here can be considered "simple" in composition. For the most part, each "square" in the diagrams given in more detail will contain an equally complex nested structure.
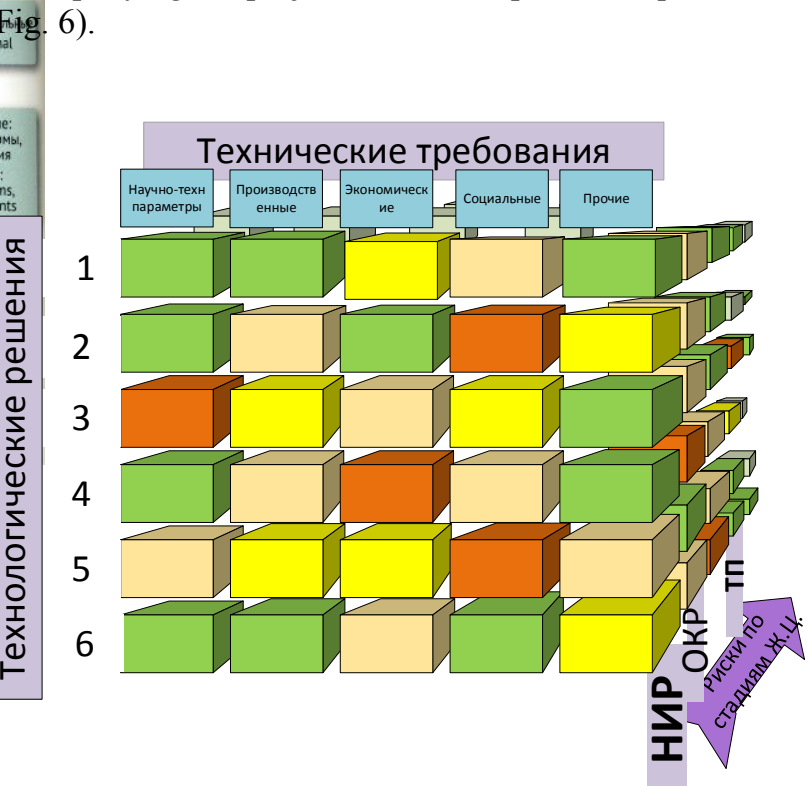

Fig. 6 Visualization of the integral risk of the NPP. Multidimensional risk matrix - Risk knowledge base.

Therefore, each group and subgroup of risks or their sources, indicated in the diagrams, and which are inherently complex, can be expanded / deciphered to the 
"elementary level" of simple risks. But this work will take a lot of time, knowledge of interdisciplinary technologies and connections, interdisciplinary definitions and interactions. And not all of them can be "digitized" or controllably minimized.

The need for classification stems from the fact that risks of different categories / hierarchies can only be managed from the appropriate levels. If at the stages of construction, operation, the "ancient method" - insurance is possible and appropriate, then at the level of developing a project or organization's strategy, it is already necessary to develop "directors' liability insurance" [3]. At present, mistakes can be avoided only by managing such risks in the categories of experience, collegiality, and a competent choice of goals when formulating strategic and systemic tasks, using systemic research and development.

\section{Human factor and risk}

But the most important thing is that in the overwhelming majority of the given "squares" the main source of risks can be considered the HF or its exposure. The essence of this influence of the HF lies in the need for human participation in decision-making, both key strategic and working tactical; in his possession at the same time a systematic approach (the ability to trace the connection "everything with everything", foresight); in psychological (un) stability against ambition and / or self-confidence, etc., etc.

For example, even possible "natural factors" and "climatic changes" can be foreseen when organizing security systems and diversifying technical water supply systems.

Regarding the Fukushima NPP: there was an earthquake, a tsunami, it would seem, what does the human factor have to do with it, where is its role in the accident or its consequences? The mistake was in the design solution for the placement of security systems (diesel generators). All this could have been foreseen and prevented, this, of course, is a human error.

A man with his decisions and actions found himself on the path of the natural disaster, but the human factor took part in this event much earlier. The greatest role of the Black Sea Fleet takes place at the very beginning of the life cycle of projects, at the level of making a strategic management decision, and it is not for nothing that the classification "Strategic risks" is put first. Miscalculation is also a human error. This means that at the time of the occurrence of an adverse event, accident, catastrophe, this notorious human factor was transferred through the previously adopted constructive and / or layout solutions. A person is a connecting link in a technical system, but human nature has the right to make mistakes, since a person is not an automaton, and you cannot turn off emotions, temperament, different upbringing,

preferences, environmental influences, etc. The influence of the human factor is inherent in all stages of the life cycle of a nuclear power plant and begins with an idea, when goals are set and arguments are made for their implementation in one way or another.

At the design stage, at the highest level of the life cycle stage hierarchy, there is a risk of goal-setting error. The damage from such mistakes is difficult to predict. From this level the largest consequences of the human factor arise. Therefore, it is much more "strategic" to identify the sources of risks and manage them (it is better to prevent them), rather than the risk itself or the developing risk situation.

Errors in regulatory documents can be ranked second in importance. It is known that the entire maritime code is written on the bones of sailors. There is a rule that says that there is no positive experience, all experience is based on mistakes. Everyone remembers that a fundamental revision of the US Nuclear Regulatory Commission (NRC) regulatory documents took place after the accident at the Three Mile Island nuclear power plant. The operator's mistake led to the curtailment of the US atomic program, and to the stagnation of nuclear power throughout the world. The entire approach to ensuring safety in nuclear power was reassessed, and probabilistic methods of safety assessment were introduced, including the human factor and common cause failures. How can you assess the degree of guilt of an American nuclear power plant operator, because he acted strictly according to the instructions? An operator error leads to an accident at one power unit or node, and an error in the regulatory documentation creates the preconditions for massive accidents. These are risks from the institutional environment as part of the infrastructure of the entire AE system.

In third place, you can put errors in the formulation of the problem at the stage of product design and design. Direct lobbying for types of installations without comprehensive expertise and comparative analyzes, taking into account consumer requirements, limiting innovative developments to the well-known formula "reference solutions", which simply leads to stagnation of promising developments, belongs to the same type of errors.

Further, in terms of the degree of risk, there are errors of designers and designers in implementation, when all possible scenarios are not taken into account or the requirements of regulatory documents are violated. A typical example would be the accident at the Chernobyl nuclear power plant. Many would very much like to make the operator a "switchman", it cannot be considered a normal design that worsens the scenario of the process when the emergency protection button is pressed. It is impossible to shift problems and design flaws onto the operating personnel.

Only on March 29, 2013, the Japanese energy company Tokyo electric power (TEPCO) acknowledged its responsibility for the accident at the Fukushima-1 nuclear power plant. The company admitted that "due to human error, the nuclear power plant was not ready for a serious accident." "Among the mistakes made, in particular, is the incorrect location of the backup power supply systems, which almost immediately went out of order and made a nuclear crisis almost inevitable" [4]. Before that, they stubbornly nodded to the tsunami, forgetting that the analysis of the safety case must take into account all external factors.

Errors in the organization of design and construction work can be attributed to the same class of errors. Such errors include, first of all, the inability of managers 
due to low technical knowledge to identify key problems and challenges, errors in concentrating resources on insignificant research and ignoring urgently needed $\mathrm{R} \& \mathrm{D}$, errors in developing criteria for competitive procedures, for example, the exaltation of economic criteria over quality indicators, organizational competence and experience, etc.

At the stage of construction and installation, the main HF is the failure to comply with the construction and installation technology and the violation of norms. Currently, such a risk of the human factor is associated with a lack of qualified personnel, constant violation of the work schedule, erroneous planning, irregularity of supplies, a complicated competitive procedure for concluding supply contracts, with the desire of managers to save on time, money, etc.

And finally, the mistakes of the operating and maintenance personnel, that "switchman" who is so fond of immediately identifying in the event of an emergency or equipment failure. The case of a generator rotor failure at one of our nuclear power plants is very eloquent: a small forgetfulness of a repairman with a plug in the oil system led to multi-million dollar losses and downtime of the power unit. But again the question arises, is a particular person really so guilty? Does the entire system not lead to such cases? Why was there no device in the design of the plug that made the next operation impossible without removing it; the usual "protection from the fool"? In aviation, similar techniques have long been used. But the designers or specialists of the service organization should think about this, and not the repairman who directly performs the work [5].

From all of the above, we can conclude that human errors are usually not limited to one level of organization structure, but affect the entire chain of organization/corporation structure (Fig. 7). I.e. error, originating in one link, manifests itself not in one link, but in a whole chain at the same time, otherwise it would be easy to prevent, localize and ultimately avoid.

So we need to look at the problem systematically, i.e. apply a Systematic approach, and try to create a project that minimizes anthropogenic risks, or even insensitive to them.

\section{Ways to overcome the influence of the HF}

It is possible to talk for a long time about using methods of psychology, psychiatry, philosophy, unmanned technologies to reduce the PF, but all of them will not give a deterministically stable result [6]. While there is one way that will allow not only to mitigate the risks associated with the HF, but to minimize other risks of nuclear energy, both based on natural physical laws and arising from the economic system.

There is nothing we can do about human nature, but we can change technical solutions.

A "perpendicular" approach to the problems of risk reduction from the Black Sea Fleet is proposed. We will not talk about automation and automation, which will not be reliable solutions (hopes for automation are futile, since there are effects of complicating systems, aging and wear of element materials, which are often of a threshold nature). The essence of the proposal is to switch to the introduction of small and medium-sized power units (NPP MSM) instead of units of large unit capacity.

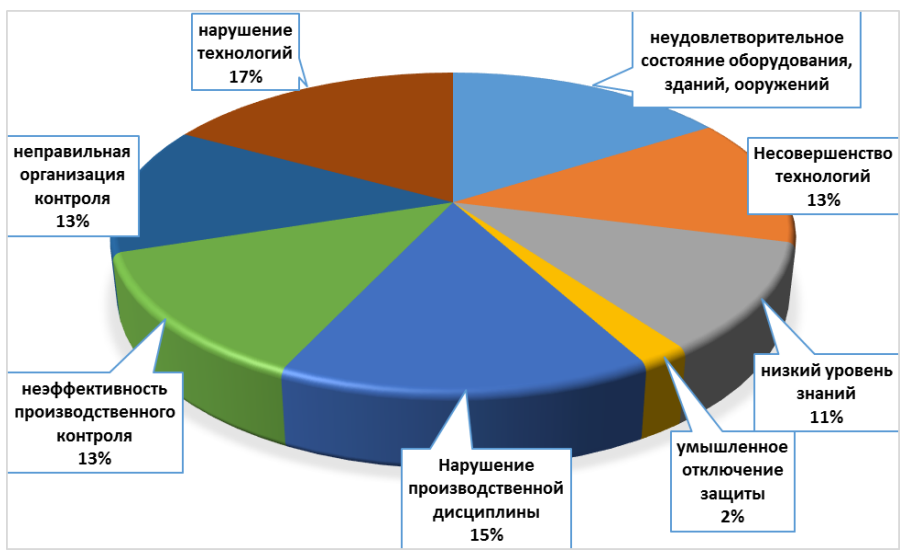

Fig. 7 Distribution of causes of accidents at high-risk facilities

In this subsection, it is proposed to consider the possibilities of a "low-risk" approach to the design of large energy facilities - to construct on the site (or in the region) several units of modular nuclear power plants of low or medium power instead of one "large" unit of a nuclear power plant, but with the same total power indicators, thereby reducing the proportion of each possible adverse event at all stages of the life cycle of a separate project/power unit (during construction, operation and decommissioning of a nuclear power plant).

What this transition gives:

1) First, the "Hattori principle" comes into operation reducing the unit capacity by a factor of 10 , for example, from $1000 \mathrm{MW}$ to $100 \mathrm{MW}$, leads to an improvement in integral safety by a factor of 1000 [7];

2) The lower capital intensity of the AS MSM units makes it easier to find an investor (investing in "small portions", reducing financial risk);

3) the possibility of a phased commissioning of power units in phases with a stepwise increase in capacity as the installation and commissioning of a group of modules is completed, which makes it possible to reduce the payback period of investments due to earlier issuance of marketable products and the beginning of loan repayment in comparison with a power unit based on a reactor large unit capacity;

4) Allows the placement of modular NPPs of low and medium power in energy consumption centers, which eliminates the cost of constructing powerful power transmission lines;

5) The possibilities of applying insurance are expanding; 6) An efficient approach would be to use modular designs;

7) Seriality will reduce capital costs.

The modularity NPP of small and medium power implies the installation of an assembled reactor block already manufactured at the plant, or the entire NPP (module) at the site. In contrast to the usual practice, when a reactor, a power unit is completely assembled on 
the site, this approach provides the possibility of organizing large-scale (conveyor) production of reactor monoblocks (tens of units per year) and a stable load of machine-building plants, which significantly reduces manufacturing costs [8]. The ultimate in utility option will be the project of "atomic battery" - a ready-made mini-NPP.

Due to the fact that several blocks of modular plants can be built simultaneously and put into operation as soon as they are ready, in a shorter time frame than large NPPs, it should be concluded that the risk of cost increases from an increase in the construction period of NPPs is reduced. First, the design features of modular nuclear power plants of low and medium power, assembled at the factory, allow the installation of the reactor plant on the site already ready for operation, which reduces the time for construction, transportation and commissioning of nuclear power plants, in contrast to high power nuclear power plants mounted directly on the site. We bypass such risks as the risks of interruptions in the supply of electricity, first of all, because (n-1) blocks / modules remain in operation if there is any emergency stop of one module or fuel overload.

In particular, Rod Adams (USA), actively promoting the idea of switching a small reactors in large power systems, argues that low-power NPPs will reduce capital costs, contrary to the popular belief that the installed kilowatt will become cheaper with an increase in the capacity of a single unit. The fact is that many small reactors will be produced, and this, willy-nilly, will require serial production of equipment and components. For the large nuclear power industry, all attempts to talk about serial production invariably ended in failure. For the United States, the option of using IMS NPPs in large centralized power systems [9] is considered as an alternative to units of large unit capacity, combining the advantages of reducing both economic and nuclearradiation risks.

5 Economic aspects of the transition to small nuclear power plants. Conceptually, the ECONOMIC EFFICIENCY of NPPs with SMR is relatively easy to justify. Rather, it is quite easy to prove that with an equal total power of AE systems with SMR and NPP of large power, the SMR system can have clear advantages of flexibility and safety. But the realization of these advantages will require serious work and serious financial, resource and intellectual investments, which are possible only with the use of the experience of developing NPP of large power, as well as nuclear power plants for space, aviation and the navy.

At present, when choosing a project, comparing and considering different alternatives, first of all, they pay attention to either overnight costs, or to specific capital costs, which is not always strategically expedient from the standpoint of a systematic approach and the life cycle of the NPP. Savings at the moment do not always translate into overall savings. The costs should be calculated for the entire life cycle of the project up to its decommissioning. Also, sometimes, the concentration of "savings" on specific capital costs leads to the "savings" of the profit itself. Simply put, if you invested less, you got less. This may be due to an increase in the payback period due to interruptions in the operation of the plant itself, the so-called operational reliability.

The proposed way of introducing NPP of small and medium power can be briefly described as follows: "now more money will be required, but then the risks will be less".

The lack of methods for quantitative assessment of the total risk, a systematic approach to them and the "division of labor" (construction and operation) does not currently allow "in conditions of economic pressure" to appreciate and accept this path.

In economics, this method of mitigating key risks in NPP projects is called power hedging, power hedge dispersal. This is a kind of "power insurance" method.

It should be emphasized that the principle of "capacity insurance" applied to NPP construction projects can achieve certain advantages in terms of mitigating many risks. Comparatively, they can be presented in the form of table 1.

In everyday life and business practice, we are accustomed to insurance: car, travel, health, space satellites, freight traffic, etc. We are confident that "by paying more now, there will be fewer problems in the future." But in nuclear power projects, we are so far deliberately taking "capacity risk" for the sake of momentary "economic benefits", without thinking about further possible and guaranteed problems (for example, decommissioning high-power units, the costs of which are estimated to be comparable to their creation ), which will be solved by our descendants (after 50-60-80 years of operation). From an ethical standpoint, this approach does not deserve a positive assessment.

In addition, it should be borne in mind that power gigantism in fire energy has not become widespread - the Kostromskaya GRES (with a unit capacity of a 1200 MW) has remained the only one of its kind; the maximum spectrum of power units lies in the range of 100 - 300 MWe.

In conclusion: the automotive theme is clear to everyone; for illustration, let's imagine, regarding the problem of the power line of power units, that the automotive industry produces only KAMAZes and buses ...

The sustainability of natural systems is based on species diversity; nuclear energy as a System is no exception. The declaration at the state level of the transition to "nature-like technologies" obliges the atomic energy community to seriously look at the ethical, economic and socio-humanitarian consequences of its activities.

\section{Conclusion}

The risks in nuclear power are very aggravating; the probability of a major catastrophe is very small, but it has a huge economic and social resonance, after which the system sometimes stops developing. Few people realize that in everyday life much more people die (in particular, on the roads) than once in a major disaster, but unfortunately, such subtleties of psychology have to be reckoned with, especially if further development is needed. Changing the psychology of people is much more difficult and labor-intensive many times over than adapting to it. And since nuclear energy is one of the few energy sources that will occupy an important place in the future, it is necessary to move on to the next stage of 
development - one step closer along the path to "riskfree nuclear power".

Table 1 Comparison of the most important risks of NPPs of large and small/medium power

\begin{tabular}{|c|c|c|}
\hline $\begin{array}{l}\text { Risks and } \\
\text { challenges }\end{array}$ & $\begin{array}{l}\text { NPP unit } 1000 \\
\text { MW }\end{array}$ & $\begin{array}{l}\text { Modular NPP of small } \\
\text { and medium power }\end{array}$ \\
\hline $\begin{array}{c}\text { the risk of } \\
\text { increased costs } \\
\text { from an increase } \\
\text { the construction } \\
\text { period }\end{array}$ & big enough & $\begin{array}{l}\text { due to its small size } \\
\text { and assembly in the } \\
\text { factory, it is reduced }\end{array}$ \\
\hline $\begin{array}{l}\text { find an investor; } \\
\text { his risk }\end{array}$ & $\begin{array}{c}\text { only large } \\
\text { companies; at } \\
\text { least 5-6 billion } \\
\text { dollars }\end{array}$ & $\begin{array}{l}\text { expansion of the circle } \\
\text { of investors, risks are } \\
\text { several times less }\end{array}$ \\
\hline $\begin{array}{l}\text { relative specific } \\
\text { capital costs }\end{array}$ & 1 & $1,2-2,0$ \\
\hline $\begin{array}{l}\text { risks of } \\
\text { electricity } \\
\text { supply } \\
\text { interruptions }\end{array}$ & $\begin{array}{c}\text { the risk is } \\
\text { present, the } \\
\text { damage is great }\end{array}$ & $\begin{array}{l}\text { the risk is present, but } \\
\text { the damage is reduced } \\
\text { several times, } \\
\text { depending on the } \\
\text { number of modules }\end{array}$ \\
\hline $\begin{array}{l}\text { use for } \\
\text { technological } \\
\text { purposes }\end{array}$ & $\begin{array}{l}\text { not applicable } \\
\text { soon }\end{array}$ & $\begin{array}{l}\text { wide possibilities of } \\
\text { approaching } \\
\text { settlements and } \\
\text { industries }\end{array}$ \\
\hline $\begin{array}{l}\text { minimum power } \\
\text { reserve in the } \\
\text { power system }\end{array}$ & $\begin{array}{l}\text { equal to unit } \\
\text { power (1000 } \\
\text { MW) }\end{array}$ & $\begin{array}{c}\text { equal to unit power } \\
(100 \sim 300 \sim 500 \\
\text { MW }) \\
\end{array}$ \\
\hline $\begin{array}{l}\text { risks associated } \\
\text { with nuclear and } \\
\text { radiation safety }\end{array}$ & $\begin{array}{l}\text { estimated by } \\
\text { probabilistic } \\
\text { methods }\end{array}$ & $\begin{array}{l}\text { deterministically, the } \\
\text { probability of risks } \\
\text { also decreases, and the } \\
\text { magnitude of the } \\
\text { damage itself } \\
\text { decreases }\end{array}$ \\
\hline $\begin{array}{l}\text { risks at the stage } \\
\text { of } \\
\text { decommissionin } \\
\text { g }\end{array}$ & $\begin{array}{l}\text { large volume of } \\
\text { dismantling, } \\
\text { high dose of } \\
\text { radiation }\end{array}$ & $\begin{array}{l}\text { large-scale } \\
\text { dismantling; the } \\
\text { likelihood of risks } \\
\text { decreases and the } \\
\text { amount of exposure } \\
\text { decreases }\end{array}$ \\
\hline export risks & $\begin{array}{l}\text { the market is } \\
\text { relatively small, } \\
\text { the competition } \\
\text { is high }\end{array}$ & $\begin{array}{l}\text { the emergence of new } \\
\text { market niches and } \\
\text { competitive } \\
\text { advantages }\end{array}$ \\
\hline $\begin{array}{l}\text { possibility of } \\
\text { civil liability } \\
\text { insurance }\end{array}$ & $\begin{array}{l}\text { not in full, } \\
\text { almost } \\
\text { impossible }\end{array}$ & $\begin{array}{l}\text { insurance is possible } \\
\text { under many programs }\end{array}$ \\
\hline $\begin{array}{l}\text { availability of } \\
\text { placement sites }\end{array}$ & limited & $\begin{array}{l}\text { within the framework } \\
\text { of regional energy, } \\
\text { almost everywhere }\end{array}$ \\
\hline $\begin{array}{c}\text { reuse of the } \\
\text { industrial site }\end{array}$ & $\begin{array}{c}\text { almost } \\
\text { impossible }\end{array}$ & possible \\
\hline $\begin{array}{c}\text { social } \\
\text { acceptability }\end{array}$ & $\begin{array}{l}\text { psychological } \\
\text { barriers } \\
\text { (especially after } \\
\text { the Chernobyl } \\
\text { and Fukushima } \\
\text { accidents) }\end{array}$ & $\begin{array}{l}\text { Possibility of visual } \\
\text { evidence of increased } \\
\text { safety of NPP of small } \\
\text { and medium power }\end{array}$ \\
\hline
\end{tabular}

It is proposed to use the method of power insurance of risks at the strategic level by switching to splitting high power units into small or medium power units. Shows its qualitative technical and economic effect; In many cases, the construction of large power units from the standpoint of risk management and economic efficiency will be irrational due to the nominally long construction and due to the huge risk of an increase in the construction period of nuclear power plant units of large unit capacity, which leads to large additional cash costs and a decrease in the flexibility of power systems. The transition to blocks of low or medium capacity will also remove many other risks described in the work.

\section{References}

1. T. Shchepetina, Yu. Udyansky, D. Chumak.

Research and classification of risks and their sources for the full life cycle of nuclear power projects //Innovative design. (2014) 8, p. 56-70.

2. Chumak D. Yu., Shchepetina T. D. Risk classification as a necessary control element in nuclear power projects // Atomic energy, v. 116, iss. 2, (2014) p. 108-113.

3. Kasyanova T. It's time to hold Incompetent managers accountable :

https://www.proatom.ru/modules.php?name=News\&file $=$ article\&sid=4341 ,22/02/2013)

4. TEPCO: The accident at the Fukushima nuclear power plant occurred due to " human error" : http://www.rosbalt.ru/main/2013/03/29/1111404.html

5. Prosvirnov A. A., Prosvirnova T. A., "System functional analysis as a basis for conceptual design", " Atomic strategy»//

http://www.proatom.ru/modules.php?name $=$ News \& file $=$ article\&sid $=33343$

6. Rylov M. I., Tikhonov M. N. / Saint Petersburg / Safety Culture at nuclear power facilities 30.09.13// http://www.proatom.ru/modules.php?name=News\&file= $\underline{\operatorname{article} \& \operatorname{sid}=4789}$

7. Energy source for human demand. Sadao Hattori /in Advanced Nuclear Systems Consuming Excess Plutonium/ Kluwer Academic Publishers, Netherlands, (1997) P. $69-77$.

8. Tepkyan G.; Zaitsev I.; Udyansky Yu. "Nuclear power plants for the spaceport: the best option".// "TEC, development strategies» (2013) 5(27).

9. "USA: A Lot of activity in the niche of small reactors»// Nuclear Renaissance (2012) 46(87) 